\title{
Transitoriness in cancer patients: a cross-sectional survey of lung and gastrointestinal cancer patients
}

\author{
Maya Shaha - Vinciya Pandian • Michael A. Choti • Eden Stotsky • \\ Joseph M. Herman • Yasmin Khan • Carol Libonati - Timothy M. Pawlik • \\ Richard D. Schulick • Anne E. Belcher
}

Received: 20 July 2009 / Accepted: 7 January 2010 /Published online: 21 February 2010

(C) Springer-Verlag 2010

\begin{abstract}
Objective Despite earlier diagnosis and advancements in treatment, cancer remains a leading cause of death in the world (13\% of all deaths according to the World Health Organization) among men and women. Cancer accounts for approximately $20 \%$ of the deaths in the USA every year. Here, we report the findings from a cross-sectional survey of psychosocial factors in lung and gastrointestinal cancer patients. The aim of the study was to explore the associations among transitoriness, uncertainty, and locus of control (LOC) with quality of life. Transitoriness is defined as a person's confrontation with life's finitude due to a cancer diagnosis.

Methods A total of 126 patients with lung or gastrointestinal cancer completed eight self-reporting questionnaires
\end{abstract}

M. Shaha $\cdot$ V. Pandian $\cdot$ C. Libonati $\cdot$ A. E. Belcher Johns Hopkins University School of Nursing,

525 North Wolfe Street,

Baltimore, MD 21205, USA

M. A. Choti • E. Stotsky · J. M. Herman - T. M. Pawlik •

R. D. Schulick

Department of Surgery,

Johns Hopkins University School of Medicine,

600 North Wolfe Street,

Baltimore, MD 21287, USA

M. Shaha $(\square)$

Department of Nursing Development and Research,

Head of Office of Nursing and Allied Health Professionals,

Inselspital Bern/University Hospital Bern,

3010 Bern, Switzerland

e-mail: Maya.Shaha@insel.ch

Y. Khan

Regeneron Pharmaceuticals Inc.,

777 Old Saw Mill River Road,

Tarrytown, NY 10591, USA addressing demographics, spiritual perspective, symptom burden, transitoriness, uncertainty, LOC, and quality of life. Results Transitoriness, uncertainty, and LOC were significantly associated with one another $(r=0.3267, p=0.0002 / r=$ $0.1994, p=0.0252$, respectively). LOC/belief in chance has a significant inverse relationship with patients' quality of life ( $r=-0.2505, p=0.0047)$. Transitoriness, uncertainty, and LOC were found to have a significant inverse relationship with patients' quality of life (transitoriness state: $r=-0.5363, p=$ 0.0000/trait: $r=-0.4629, p=0.0000$ /uncertainty: $r=-0.4929$, $p=0.0000 /$ internal LOC: $r=0.1759, p=0.0489 /$ chance LOC: $r=-0.2505, p=0.0047$ ).

Conclusion Transitoriness, uncertainty, and LOC are important concepts as they adversely influence patients' quality of life. Incorporating this finding into the care of cancer patients may provide them with the support they need to cope with treatment and maintenance of a positive quality of life.

Keywords Cancer Psychosocial issues .

Cross-sectional survey - Gastrointestinal and lung cancer patients $\cdot$ Transitoriness $\cdot$ Quality of life

\section{Introduction}

The fact that cancer may be fatal remains one of its most significant characteristics [1]. In particular, many patients with lung and gastrointestinal (GI) cancer have a poor prognosis [2]. Annually, approximately 300,000 men and women die of lung or GI cancer in the USA [2]. As a result, these patients face life's transitoriness, which constitutes an important aspect of life after a cancer diagnosis [3, 4]. Transitoriness describes cancer patients' realization that they may die as a result of their disease and that death may 
come sooner than expected. Fear of death is part of this experience, but patients tend to emphasize their fear of burdening their families with the potentiality for death [5]. Qualitative studies indicate that a sense of transitoriness finds expression in increased anxiety, anger, uncertainty [5, 6], and a perception of lessened control, which, in turn, may lead to impaired self-confidence and even depression [7, 8]. Transitoriness also contributes to an increased motivation for change and keen interest in life, as manifested in altered life priorities and goals $[5,6]$. Eventually, patients aim to find a way to accept death as part of the disease and to incorporate this awareness into their everyday life [1]. They become aware that they need to put their affairs in order, to ensure that the household will continue to function, and/or that family and friends are not left with unsolvable and insurmountable problems $[4,9]$.

Besides the confrontation with life's finitude, psychological factors such as uncertainty, anxiety, and distress can significantly and adversely influence cancer patients' quality of life $[10,11]$. Uncertainty is defined in this context as people's ability to determine the meaning of illness-related events [12]. Being confronted with uncertainty can motivate people to attempt to adjust to the changing demands associated with their illness [12, 13]. These studies have focused predominantly on cancer survivors, women with breast cancer or men with prostate cancer $[14,15]$. Cancer patients also experience changes in locus of control [16]. The term "locus of control" (LOC) refers to where individuals believe their control to be regarding their health [17]. A higher degree of control over decisions and a higher level of influence over the illness situation are assumed to positively affect individuals' quality of life. Validation studies conducted by Wallston $[17,18]$ with patients with arthritis, chronic pain, diabetes, and cancer indicated that cancer patients had a higher belief in chance ${ }^{1}$ than patients with other chronic diseases. A cross-sectional study employing a convenience sample of 95 African American demonstrated that a higher belief in powerful others was related to a greater self-esteem [7]. Quality of life in cancer patients has often been studied regarding treatments and symptoms $[19,20]$. However, patients' sense of transitoriness and its relationship to uncertainty, LOC, and quality of life as symptoms of a cancer diagnosis in patients with lung and GI cancer have yet to be examined in detail. Studies concerning the sense of transitoriness due to a cancer diagnosis and its influence on patients' quality of life have been predominantly qualitative in nature $[1,21]$. Information about the sense of transitoriness is necessary if we are to fully comprehend how patients experience their disease and cancer treatment.

\footnotetext{
${ }^{1}$ The subscale 'chance LOC' measures the extent to which patients believe their health and illness situation is due to luck and chance [8].
}

Therefore, a cross-sectional study was conducted to explore the interrelationships among transitoriness, uncertainty, LOC, and quality of life in lung and GI cancer patients. In particular, we have addressed the hypotheses that cancer patients' sense of transitoriness is related to uncertainty and LOC and that their sense of transitoriness, uncertainty, and LOC is negatively associated with quality of life.

\section{Patients and methods}

Study design and setting

This cross-sectional study was conducted at the Sidney Kimmel Comprehensive Cancer Center and the Bayview Medical Center at the Johns Hopkins Medical Institutions (Baltimore, MD, USA), a large teaching facility in the USA, and was approved by its institutional review board.

\section{Patients}

A total of 193 patients with a diagnosis of lung or GI cancer at various stages who visited the Center between May 2006 and August 2007 were enrolled in the study. The inclusion criteria for this study were: (a) of any ethnic group, (b) $>21$ years of age, (c) able to speak and read English, (d) inpatient or outpatient at this teaching facility, (e) not in hospice care. Patients were approached by study team members while they were inpatients or were waiting for consultations or treatments. After patients had signed the consent form, they received the set of questionnaires described below and then completed them either on site or at home.

\section{Instruments}

The four main variables in this study, i.e., a sense of transitoriness, uncertainty, LOC, and quality of life, were assessed by means of five questionnaires administered to the patients. Two other questionnaires were used to assess patients' physical symptoms and spiritual practices.

\section{Transitoriness}

Scales for assessing transitoriness have yet to be developed, but patients' fear of death after a cancer diagnosis has been assessed in the past by using anxiety measures such as the State-Trait Anxiety Scale [22]. This scale has been enhanced to include measures for the states and traits of anger, depression, and curiosity [23]. This instrument, therefore, was considered to provide information on the attributes of transitoriness, i.e., fear of death, anger at the situation, curiosity for life, and a potential for depression as a result of an overwhelming sense of transitoriness $[3,5]$. 
The State-Trait Personality Inventory is valid with a reliability of $r=0.78$ to $r=0.90$ [24] and consists of eight Likert-based subscales, each totaling in ten items. The responses range from 80 to 320 points. Higher scores indicate a stronger sense of transitoriness.

\section{Uncertainty}

Mishel's Uncertainty in Illness scale [25] was used to measure uncertainty, i.e., the extent to which people are able to determine the meaning of disease-related events [12]. This Likert-type questionnaire consists of 33 items, with responses ranging from 32 to 160 points with higher scores indicating more uncertainty. This is a valid instrument with a reliability of $r=0.90$ [25].

\section{Locus of control}

The Multidimensional Health LOC Scale [17] was employed to measure patients' perception of LOC, i.e., the extent to which people believe their health is dependent on their behavior [17]. There are three different forms of this scale: namely A, B, and C. Forms A and B are purported to be interchangeable and measure people's general beliefs about health LOC. The recommendation is to always use form $\mathrm{C}$, which is condition specific, in conjunction with either A or B [26]. Forms B and C were used. Form B encompasses three subscales: internal LOC, chance, and powerful others. Form $\mathrm{C}$ encompasses four subscales: internal LOC, chance, doctors, and other people LOC [27]. Form B's Cronbach's $\alpha$ ranges from 0.60 to 0.70 [26]; form C's Cronbach's $\alpha$ ranges from 0.70 to 0.87 . These two forms together consist of 36 Likert scale items, with responses ranging from six to 36 for the subscales internal, chance, and powerful others of forms $\mathrm{B} / \mathrm{C}$ and from 6 to 18 for the subscales doctors and other people responses. Neither form $\mathrm{B}$ nor $\mathrm{C}$ adds up to a total score, but higher scores indicate higher levels of control.

\section{Quality of life}

The Functional Assessment of Cancer Therapy (FACT-G) developed by Cella et al. [28] was used to assess patients' quality of life. The FACT-G version 4 measures people's subjective assessment of their physical, social, emotional, and functional well-being. The FACT-G version 4 consists of 27 items with a five-point Likert-type response scale with a Cronbach's $\alpha$ of 0.80 [28]. The scores for the physical, social, and functional well-being subscales range between 0 and 28 . The scores of the emotional well-being subscale range between 0 and 24 . The sum score for the total scale ranges from 0 to 108 [28]. Higher scores indicate increased quality of life.

\section{Other instruments}

Patients' symptom burden was assessed using the MD Anderson Symptom Inventory (MDASI) [29]. This scale assesses current symptoms in addition to the related distress and interference in usual activities [29]. The MDASI consists of 13 Likert-type questions with responses ranging from 0 to 130 , and higher scores indicate increased symptom burden. Participants also provided an overview of their spiritual practices with the Spiritual Perspective Scale [30]. This scale measures people's views and behaviors that are due to the people's belief in some dimension of transcendence or a spiritual guide beyond human beings [30]. It consists of ten Likert-type questions with responses ranging from 10 to 60 with higher scores indicating more frequent spiritual practice.

Data analysis

Data were entered and analyzed using Stata Intercooled $9{ }^{\circledR}$, a software package for descriptive and inferential statistics. Apart from the demographics scale, sum scores were calculated according to the manuals and specifications of the questionnaire developers. The findings obtained from these instruments were analyzed using means and standard deviations, calculated for the whole sample and women and men separately. Pearson correlations between quality of life and transitoriness, uncertainty, and LOC were calculated separately, with $p$ values of $\leq 0.05$ being considered significant. Multivariate linear regression was used to assess the potential associations between transitoriness and quality of life after adjusting for sex and disease site.

\section{Findings}

\section{Demographics}

Of the 193 cancer patients enrolled in the present study, $39 \%(n=75)$ completed the set of questionnaires on site. The remainder $(n=118)$ completed them elsewhere, and $33 \%(n=64)$ of these patients mailed their set of questionnaires back. Of the 139 returned questionnaires, 65.3\% $(n=$ 126) were fully completed and usable for analysis. This overall response rate was achieved by follow-up phone calls by the study team.

The final sample size was $n=126(51 \%$ women $)$ with an average age of 61.4 years $(\mathrm{SD}=9.59$; men: mean $=$ 61.7 years, $\mathrm{SD}=9.27$; women: mean $=61.1$ years, $\mathrm{SD}=$ $9.95)$, and $80 \%$ were married. The majority of the participants were Caucasian (89\%). The ethnic variability in this sample reflected the demographics of the center where the study was conducted. 
Colorectal, lung, and pancreatic cancer were almost equally represented in the study population. A total of 35 participants ( $40 \%$ women) had been diagnosed with colorectal cancer, 38 (55\% women) with lung cancer, and 30 (50\% men) with pancreatic cancer. A fourth group of 23 patients $(61 \%$ women) had liver (22\%), stomach (39\%), gallbladder (35\%), or anal cancer $(4 \%)$. The majority of the participants $(34 \%$; $60 \%$ women) presented with stage IV disease. Stage I was identified in 11 patients ( $27 \%$ women), stage II in 12 patients (33\% women), and stage III in 29 patients ( $48 \%$ women). In the case of 31 patients ( $55 \%$ women), the disease was not staged. Among those with colorectal, lung, or pancreatic cancer, more than half presented with stage IV disease. In the group with various cancer diseases, only a third presented with stage IV disease. Three quarters of the participants had been diagnosed $<15$ weeks prior to study enrollment (mean $=$ $14.79, \mathrm{SD}=22.90)$. The majority of our participants $(73 \%)$ had had a surgical intervention and were undergoing chemotherapy treatment $(92.9 \%)$; less than half the participants were in radiation therapy (46.8\%). About half of all participants $(n=58)$ were receiving a combination of chemotherapy and radiation. Only nine patients had neither received chemotherapy nor radiation therapy treatments. A symptom burden of $41.48(\mathrm{SD}=30.20$; range $=0-121)$ for the whole sample $(n=126)$ indicated that patients suffered from at least four symptoms out of a total of 13, whether physical, such as nausea, or psychosocial, such as impaired mood. Women's $(n=64)$ mean symptom burden was 41.86 $(\mathrm{SD}=29.02)$ and men's $(n=62)$ was $43.06(\mathrm{SD}=31.90)$. The participants most frequently noted fatigue (mean $=3.66, \mathrm{SD}=$ 3.84 ), reduction on their ability for general activity (mean $=$ $3.25, \mathrm{SD}=2.85)$, and restricted household work (mean $=3.21$, $\mathrm{SD}=2.97$ ). The least concern was vomiting (mean $=0.52$, $\mathrm{SD}=1.46)$.

Eighty-two percent of the participants (52 women; 51 men) reported Christian faith. Across all participants, a mean of $43.58(\mathrm{SD}=14.09)$ for the Reed Spiritual Perspective Scale [30] was obtained. Women $(n=64$, mean $=46.07$, $\mathrm{SD}=13.79$ ) reported a slightly higher level of spiritual practice than men $(n=62$, mean $=41.18, \mathrm{SD}=14.07)$, but this difference was only marginally significant $(t=-1.9215$, degrees of freedom $=118, p=0.0571$; Table 1).

\section{Nonresponders}

Of the 193 patients approached, a total of 67 patients (35 women) did not complete the survey. The majority of these patients experienced disease progression, which prevented them from participating in the study. The average age of the nonresponders was 61.66 years (range 32-87 years). Approximately, half of these patients $(n=32)$ were married, but over a third did not indicate their marital status $(n=26)$. Similarly, the majority of these patients $(n=48)$ did not
Table 1 Demographics of the study population $(n=126)$

\begin{tabular}{|c|c|}
\hline Variables & All $(n=126)$ \\
\hline \multicolumn{2}{|l|}{ Gender } \\
\hline Women & 64 \\
\hline Men & 62 \\
\hline Age in years [mean (SD)] & $61.36(9.59)$ \\
\hline \multicolumn{2}{|l|}{ Marital relations } \\
\hline Married & 101 \\
\hline Divorced & 8 \\
\hline Widowed & 8 \\
\hline Single & 9 \\
\hline \multicolumn{2}{|l|}{ Ethnicity } \\
\hline Caucasian & 111 \\
\hline African-American & 9 \\
\hline Asian & 2 \\
\hline Hispanic & 2 \\
\hline Other & 1 \\
\hline \multicolumn{2}{|l|}{ Disease stage } \\
\hline Stage 1 & 11 \\
\hline Stage 2 & 12 \\
\hline Stage 3 & 29 \\
\hline Stage 4 & 43 \\
\hline Not staged & 31 \\
\hline Symptom burden [mean (SD) $]^{\mathrm{a}}$ & $42.45(30.35)$ \\
\hline \multicolumn{2}{|l|}{ Religious affiliation } \\
\hline Christian & 103 \\
\hline Muslim & 1 \\
\hline Jewish & 8 \\
\hline Other & 14 \\
\hline Spirituality [mean (SD)] ${ }^{\mathrm{b}}$ & $43.58(14.09)$ \\
\hline
\end{tabular}

The numbers in the table are counts

${ }^{\text {a }}$ Score on the MD Anderson Symptom Inventory [47]

${ }^{\mathrm{b}}$ Score on the Spiritual Perspective Scale [48]

provide information on their educational background. However, 15 patients indicated undergraduate and higher education. More than two thirds of the patients $(n=44)$ did not indicate their spiritual affiliation. A third of the patients $(n=21)$ stated that they were of Christian faith; one person was of the Islamic and one person of the Jewish faith. The majority of the nonresponders were Caucasian $(n=43)$ along with one Hispanic and one Asian person. Unfortunately, 17 African Americans decided against participation due to concerns about confidentiality. ${ }^{2}$ Of the nonrespond-

\footnotetext{
${ }^{2}$ There was a passage in the standard consent form employed by the Johns Hopkins Medical Institutions that the participant's general/ family practitioner outside the hospital may be informed of health care data if requested. For the African American people, this particular passage was unacceptable, and no satisfactory alternative could be found.
} 
ers, 16 patients had been diagnosed with bile duct cancer; $n=13$ patients had lung cancer, and an equal group $(n=13)$ were patients with colorectal cancer. However, 24 patients did not identify the cancer site.

\section{Transitoriness}

The mean sum score for the state portion of the State-Trait Personality Inventory [24] was $75.64(\mathrm{SD}=13.39)$ and for the trait portion was $77.15(\mathrm{SD}=11.11)$. Overall, men and women demonstrated approximately the same levels of state and trait transitoriness. However, men tentatively had higher trait transitoriness than women $(p=0.0506)$. Equally, men had higher levels of trait anger than women ( $p=$ 0.0456). The neutral depression threshold in the state part was given at mean $=14.37(\mathrm{SD}=5.89)$ for men and mean $=$ $14.79(\mathrm{SD}=5.05)$ for women [24]. A mean of $19.57(\mathrm{SD}=$ 6.90) for men and a mean of $22.18(\mathrm{SD}=7.05)$ for women indicated mild depression [24]. With regard to our sample, neither men nor women were close to the mild depression level given as the threshold for state depression. For trait depression threshold, mean $=17.58(\mathrm{SD}=6.57)$ for men and mean $=18.52(\mathrm{SD}=5.88)$ for women were reported [24]. These values were greater than the ones of our participants. Cronbach's $\alpha$ was calculated as 0.9307 for the state portion and 0.9383 for the trait portion (Table 2).

\section{Uncertainty}

The uncertainty scale sum score was calculated for 32 items as indicated by Mishel [12]. Our study participants $(n=126)$ demonstrated a mean uncertainty level of $87.31(\mathrm{SD}=$ 10.41 ), with a $95 \%$ confidence interval of $[85.47 ; 89.16]$. Their perception of the situation's ambiguity was calculated at $32.62(\mathrm{SD}=9.13)$, and the complexity was found to be $27.04(\mathrm{SD}=3.45)$. The study participants considered the inconsistency of the information at $14.59(\mathrm{SD}=3.17)$ and the illness' unpredictability at $13.06(\mathrm{SD}=3.64)$. Men

Table 2 Transitoriness in the study population $(n=126)$

\begin{tabular}{lll}
\hline Transitoriness & \multicolumn{2}{l}{ Present study [mean (SD)] } \\
\cline { 2 - 3 } & Men $(n=62)$ & Women $(n=64)$ \\
\hline State anxiety & $18.58(6.19)$ & $18.38(5.91)$ \\
Trait anxiety & $17.02(5.82)$ & $16.69(4.74)$ \\
State anger & $12.56(4.65)$ & $11.89(3.57)$ \\
Trait anger & $16.26(4.71)$ & $14.81(3.21)$ \\
State curiosity & $27.40(5.76)$ & $26.89(5.58)$ \\
Trait curiosity & $30.23(5.82)$ & $28.67(6.21)$ \\
State depression & $18.24(6.12)$ & $17.37(5.81)$ \\
Trait depression & $15.61(5.85)$ & $15.08(4.94)$ \\
\hline
\end{tabular}

demonstrate a mean level of uncertainty of $87.32(\mathrm{SD}=$ $9.50)$ and are similar to women with a mean of $87.29(\mathrm{SD}=$ 11.30). Cronbach's $\alpha$ was 0.8728 .

Locus of control

Medium levels emerged for men and women regarding internal LOC, chance, and powerful others. The findings of the "doctors" subscale indicated that the study participants relied on health care professionals, whereas other people appeared to have a less important role regarding LOC. Men and women differed in the levels of LOC. Only the difference between LOC and "significant others" emerged as significant $(p=0.0035)$. Cronbach's $\alpha$ was 0.6458 for form B and 0.7980 for form C (Table 3).

\section{Quality of life}

In this sample $(n=126)$, the mean self-reported level of quality of life as measured by the FACT-G was 41.64 (SD= 8.91). The men report a mean level of quality of life of 42.15 $(\mathrm{SD}=9.66)$, and the women reported a slightly lower mean of $40.99(\mathrm{SD}=8.53)$. Cronbach's $\alpha$ was 0.9142 (Table 4).

\section{Association among the main variables}

No significant differences were found among patients with lung, colorectal, pancreatic, and other GI cancer regarding transitoriness, uncertainty, LOC, or quality of life. Calculation of the Pearson correlations demonstrated significant inverse associations between quality of life and transitoriness, uncertainty, and chance LOC. A significant positive relationship was found between quality of life and internal LOC. In addition, quality of life was found to be inversely correlated with symptom burden as measured by the MDASI, transitoriness, and uncertainty. Findings with $p$ values of $<0.05$ are reported (Table 5).

Multivariate linear regression was used to assess the association between quality of life and transitoriness while adjusting for gender and cancer site. After adjustment, the multivariate linear regression analysis results were found to explain 32\% ( $r$-squared) or 30\% (adjusted $r$-squared) of the variance in quality of life $(F(4,121)=14.23, p=0.0000)$ for our sample of $n=126$ (Table 6).

\section{Discussion}

Overall, the levels of transitoriness state and trait, uncertainty, and LOC in our population were found to be moderate to high in comparison to the norms provided by Spielberger [24], Mishel [12], and Wallston [17, 18] on the respective measurements. This study sample consisted of an 
Table 3 Locus of control (LOC) results for the study population $(n=126)$

\begin{tabular}{llc}
\hline & \multicolumn{2}{l}{ Present study [mean (SD)] } \\
\cline { 2 - 3 } & \multicolumn{1}{c}{ Men $(n=62)$} & Women $(n=64)$ \\
\hline LOC form B & & \\
Internal & $24.52(4.41)$ & $22.66(5.90)$ \\
Chance & $16.48(5.81)$ & $18.37(5.36)$ \\
Powerful others & $24.87(5.10)$ & $23.23(5.50)$ \\
LOC form C & & \\
Internal & $17.65(6.80)$ & $16.55(6.57)$ \\
Chance & $17.40(8.00)$ & $20.09(7.65)$ \\
Doctors & $15.05(2.40)$ & $14.41(2.58)$ \\
Other people & $11.92(3.61)$ & $9.94(3.842)$ \\
\hline
\end{tabular}

even number of men and women. Among this sample, lung and GI cancer are evenly distributed. The majority of the study participants had stage IV disease. This may be due to the group of patients with pancreatic cancer. Most of our study population had been diagnosed with stage IV disease fewer than 15 weeks prior to participation. A majority of the participants also were undergoing surgical intervention, chemotherapy, and/or radiation therapy. The levels of state and trait transitoriness and uncertainty in the study participants may be thus explained. Having cancer is exceedingly stressful [10], produces high levels uncertainty $[9,10]$, and induces anxiety [10], anger [31], and a sense of transitoriness [1, 5]. Being in treatment for cancer is considered highly stressful, provoking anxiety and uncertainty depending on the extent of the changes in body and lifestyle due to the disease, as well as the degree of involvement patients experience in treatment decisionmaking processes $[32,33]$.

In this sample, surprisingly, the depression levels were not found to exceed the mild depression threshold [24]. However, because information concerning the specifics of medication or antidepression treatment were not collected, it is difficult to interpret these findings clinically. Nevertheless, depression remains an important psychosocial symptom that is prevalent in cancer patients and influences the coping process $[7,10]$.
The study participants experienced high levels of uncertainty $($ mean $=87.31, \mathrm{SD}=10.41)$. Three quarters of our sample had received the diagnosis of cancer less than 15 weeks prior to participation in the study. Also, the majority of the study participants were undergoing anticancer treatment. These aspects may explain the levels of uncertainty in the study participants. Uncertainty has been found among patients with prostate cancer who are undergoing watchful waiting [34, 35] or among survivors of breast cancer [15]. Among the latter group, the uncertainty levels (mean $=57.08, \mathrm{SD}=10.14)$ were lower than the ones of our study participants [15]. Undergoing anticancer treatment has been described as being a distressing situation for patients and their families, as the situation is found to be unstable and not predictable [32, 33].

The LOC levels in our sample do not exceed the referential data provided by Wallston $[17,18]$ that were obtained upon the validation processes of forms B and C. Our study participants' LOC levels as assessed by form B were slightly lower than the ones found in Taiwanese cancer patients [36] and the ones found in African American cancer patients [37]. Evidence exists that higher belief in chance, i.e., to what extent people believe that their health and illness situation is due to pure luck and chance, may influence screening practices for breast cancer among women $[38,39]$. It can be argued that the importance of belief in chance that was found in our sample may also be due to the many unknown aspects of lung and GI cancer and that investigations into the etiology of the cancer may not produce conclusive results $[40,41]$. These uncertainties associated with cancer and its etiology are considered difficult to accept and may impair patient coping [7].

In our sample, the significant association among a sense of transitoriness, uncertainty, and LOC supports results from qualitative studies that indicate such a relationship [1, 5, 9]. A sense of transitoriness, uncertainty, and LOC showed a statistically significant inverse correlation with quality of life. The interrelationship of uncertainty with quality of life in this sample $(r=-0.4929, p=0.0000)$ was congruent with that reported in the literature $(r=-0.462)$ [13]. Similarly, research employing the positive and negative affect schedule has indicated a relationship ( $r=$ $0.26)$ between quality of life and LOC $[42,43]$. However,
Table 4 Quality-of-life results for the study population

\begin{tabular}{lccr}
\hline & $\begin{array}{l}\text { All }(n=126) \\
\text { Mean (SD) }\end{array}$ & $\begin{array}{l}\text { Women }(n=64) \\
\text { Mean (SD) }\end{array}$ & $\begin{array}{l}\text { Men }(n=62) \\
\text { Mean (SD) }\end{array}$ \\
\hline Quality of life (FACT) & $41.56(9.08)$ & $40.99(8.53)$ & $42.15(9.66)$ \\
Subscale physical well-being & $19.17(5.82)$ & $18.52(5.64)$ & $19.84(5.98)$ \\
Subscale social/family well-being & $11.44(2.39)$ & $11.49(2.21)$ & $11.39(2.58)$ \\
Subscale emotional well-being & $6.25(1.65)$ & $6.29(1.51)$ & $6.20(1.79)$ \\
Subscale functional well-being & $4.70(1.67)$ & $4.69(1.61)$ & $4.71(1.76)$ \\
\hline
\end{tabular}


Table 5 Statistically significant correlations among the main variables $(n=126)$ $p$ values $\leq 0.05$ for variable $1 \mathrm{vs}$. variable 2 were considered significant

\begin{tabular}{lll}
\hline Dependent variable & Independent variables & Correlation \\
\hline Transitoriness state & Uncertainty & $r=0.3267, p=0.0002$ \\
Transitoriness trait & Uncertainty & $r=0.2678, p=0.0024$ \\
Transitoriness state & Chance locus of control (form B) & $r=0.1994, p=0.0252$ \\
Transitoriness trait & Chance locus of control (form B) & $r=0.2280, p=0.0102$ \\
Quality of life (FACT) & Transitoriness state & $r=-0.5363, p=0.0000$ \\
Quality of life (FACT) & Transitoriness trait & $r=-0.4629, p=0.0000$ \\
Quality of life (FACT) & Uncertainty & $r=-0.4929, p=0.0000$ \\
Quality of life (FACT) & Internal locus of control (Form B) & $r=0.1759, p=0.0489$ \\
Quality of life (FACT) & Chance locus of control (Form B) & $r=-0.2505, p=0.0047$ \\
Quality of life (FACT) & Chance locus of control (Form C) & $r=-0.1816, p=0.0418$ \\
Quality of life (FACT) & Symptom burden & $r=-0.6701, p=0.0000$ \\
\hline
\end{tabular}

studies have not yet shown that patients' belief in chance significantly reduces their perception of quality of life. Studies focusing on this factor may yield important information, enabling a better understanding of cancer patients.

Although our study was sufficiently powered, stratification of the results by cancer site was not possible because each of the four disease groups in this sample was too small. In addition, the majority of the participants were Caucasian. Although the study was open to all patients from diverse ethnic backgrounds, only a very small number of African American, Hispanic, and Asian people could be enrolled. Further investigation of the potential effect of the type of cancer on the parameters assessed here including ethnic group is necessary in order to enable us to determine their relationship to transitoriness. Although transitoriness has been associated with patient outcomes such as quality of life [44], the extent to which this relationship was observed in the present study is surprising. The fact that transitoriness accounted for $32 \%$ of the variability in quality of life is a novel finding. These results suggest that psychosocial factors are important for all patients and need to be considered if quality cancer care is to be provided. In future studies, the association of transitoriness with other psychosocial factors in patients with other cancers, such as head and neck cancer, and of diverse ethnic backgrounds should be examined along with various psychosocial factors and their association with quality of life over time.

\section{Conclusion}

The findings from this cross-sectional study demonstrate that patients with lung and GI cancer experience medium to high levels of transitoriness, uncertainty, and LOC, which adversely influence patients' quality of life. Therefore, it is important to consider these factors as psychosocial symptoms and include them in cancer care. It is necessary not only to assess physical symptoms systematically and periodically but also psychosocial factors including a sense of transitoriness, uncertainty, and LOC coupled with inquiries as to the patients' current worries and preoccupations.

Further study of a sense of transitoriness, uncertainty, LOC, and their relationship to quality of life in lung and GI cancer patients over the disease trajectory in relation to other symptoms is necessary in order to obtain a more thorough understanding of the patients' experience and needs. Thus, it will be possible to develop and implement instruments that help to systematically assess these factors on a regular basis to gain a better understanding of patients' quality of life and their coping with the disease. More comprehensive information about the disease situation can be obtained, which can lead to earlier recognition of clinically relevant anxiety or depression. In addition, clinically relevant resources such as patient curiosity or support by significant others may be identified. This would provide for earlier and important referrals to be obtained if necessary.
Table 6 Transitoriness and quality of life $(n=126)$

\begin{tabular}{lcccccr}
\hline Quality of life (FACT) & Coef. & Std. err. & $T$ & \multicolumn{2}{c}{$P>\left.\right|_{\mid} t_{\mid}^{\prime}$} & \multicolumn{2}{c}{$95 \%$ conf. interval } \\
\hline Sex & -2.28 & 1.39 & -1.64 & 0.103 & -5.02 & 0.47 \\
Cancer site & -0.47 & 0.64 & -0.74 & 0.46 & -1.75 & 0.80 \\
Transitoriness State & -0.28 & 0.07 & -3.82 & 0.000 & -0.42 & -0.13 \\
Transitoriness Trait & -0.16 & 0.09 & -1.80 & 0.075 & -0.34 & 0.02 \\
_cons & 77.35 & 5.43 & 14.26 & 0.00 & 66.60 & 88.09 \\
\hline
\end{tabular}


Acknowledgments We thank the study participants for their generous support. We also thank Julie Brahmer, MD, David Ettinger, MD, and Charles Rudin, MD; JoAnn Coleman, CRNP, as well as the nurses at the Sidney Kimmel Comprehensive Cancer Center at the Johns Hopkins Hospital. Thanks go to Kevin Frick, PhD, at the Johns Hopkins University Bloomberg School of Public Health, who, together with Yen-Yi Ho, $\mathrm{Ph}(\mathrm{c})$, and Haley Hadlin from the Collaborative Center for Intervention Research (CCIR) Biostatistics Consultation Center of the Johns Hopkins University School of Nursing, provided methodological and statistical support. Thanks also go to Kathleen Griffith, PhD, RN, and Fiona Chandran-Laird, PhD, for their comprehensive critiques of the manuscript and Deborah McClellan from the CCIR Editorial Consultation Service of the Johns Hopkins University School of Nursing for providing extensive editorial consultation.

Financial and other disclosures This postdoctoral study was supported by the Swiss Cancer League and the Dorothy Evans Lyne Fund. The supporting institution was the Johns Hopkins University School of Nursing, Baltimore, MD, USA. This work was also supported in part by the Immix Foundation and the Larry "Tex" Silverman Memorial Fund.

\section{References}

1. Cohen MZ, Williams L, Knight P et al (2004) Symptom masquerade: understanding the meaning of symptoms. Support Care Cancer 12:184-190

2. American Cancer Society (2008) Cancer facts and figures 2008. American Cancer Society, Atlanta

3. Maliski SL, Sarna L, Evangelista L, Padilla G (2003) The aftermath of lung cancer: balancing the good and bad. Cancer Nurs 26:237-244

4. Coyle N (2006) The hard work of living in the face of death. J Pain Symptom Manage 32:266-274

5. Shaha M, Cox CL (2003) The omnipresence of cancer. Eur J Oncol Nurs 7:191-196

6. Westman B, Bergenmar M, Andersson L (2006) Life, illness and death-existential reflections of a Swedish sample of patients who have undergone curative treatment for breast or prostatic cancer. Eur J Oncol Nurs 10:169-176

7. Stiegelis HE, Hagedoorn M, Sanderman R et al (2003) Cognitive adaptation: a comparison of cancer patients and healthy references. Br J Health Psychol 8:303-318

8. Naus MJ, Price EC, Peter MP (2005) The moderating effects of anxiety and breast cancer locus of control on depression. J Health Psychol 10:687-694

9. Winterling J, Wasteson E, Glimelius B et al (2004) Substantial changes in life: perceptions in patients with newly diagnosed advanced cancer and their spouses. Cancer Nurs 27:381-388

10. Zabora J, BrintzenhofeSzoc K, Curbow B et al (2001) The prevalence of psychological distress by cancer site. Psychooncology 10:19-28

11. Sammarco A (2003) Quality of life among older survivors of breast cancer. Cancer Nurs 26:431-438

12. Mishel MH (1997) Uncertainty in acute illness. Ann Rev Nurs Res 15:57-80

13. Sammarco A (2001) Perceived social support, uncertainty, and quality of life of younger breast cancer survivors. Cancer Nurs 24:212-219

14. Gil KM, Mishel MH, Germino B et al (2005) Uncertainty management intervention for older African American and Caucasian long-term breast cancer survivors. J Psychosoc Oncol 23:3-21
15. Wonghongkul T, Dechaprom N, Phumivichuvate L, Losawatkul S (2006) Uncertainty appraisal coping and quality of life in breast cancer survivors. Cancer Nurs 29:250-257

16. Henderson JW, Donatelle RJ (2003) The relationship between cancer locus of control and complementary and alternative medicine use by women diagnosed with breast cancer. Psychooncology 12:59-67

17. Wallston KA, Stein MJ, Smith CA (1994) Form C of the MHLC scales: a condition-specific measure of locus of control. J Pers Assess 63:534-553

18. Wallston KA, Wallston BS (1981) Health locus of control scales. In: Lefcourt H (ed) Research with the locus of control construct, vol 1. Academic, New York, pp 189-244

19. Booker R, Olson K, Pilarski LM et al (2009) The relationships among physiologic variables, quality of life, and fatigue in patients with multiple myeloma. Oncol Nurs Forum 36:209-216

20. Temel JS, Greer JA, Goldberg S et al (2009) A structured exercise program for patients with advanced non-small cell lung cancer. J Thorac Oncol 4:595-601

21. Little M, Sayers EJ (2004) The skull beneath the skin: cancer survival and awareness of death. Psychooncology 13:190-198

22. Robinson PJ, Wood K (1983) Fear of death and physical illness: a personal construct approach. Death Educ 7:213-228

23. Spielberger CD, Ritterband LM, Sydeman SJ et al (1995) Assessment of emotional states and personality traits: measuring psychological vital signs. In: Butcher JN (ed) Clinical personality assessment: practical approaches. Oxford University, New York

24. Spielberger CD (1995) In: Spielberger CD (ed) Scoring information for the revised STPI. University of South Florida, Tampa

25. Mishel MH (1997) Uncertainty in illness scales. University of North Carolina, Chapel Hill

26. Wallston KA (2005) The validity of the multidimensional health locus of control scales. J Health Psychol 10:623-631

27. Rock DL, Meyerowitz BE, Maisto SA, Wallston KA (1987) The derivation and validation of six multidimensional health locus of control scale clusters. Res Nurs Health 10:185-195

28. Cella DF, Tulsky DS, Gray G et al (1993) The functional assessment of cancer therapy scale: development and validation of the general measure. J Clin Oncol 11:570-579

29. Cleeland CS, Mendoza TR, Wang XS et al (2000) Assessing symptom distress in cancer patients: the M.D. Anderson symptom inventory. Cancer 89:1634-1646

30. Reed PG (1987) Spirituality and well-being in terminally ill hospitalized adults. Res Nurs Health 10:335-344

31. Bertero C, Vanhanen M, Appelin G (2008) Receiving a diagnosis of inoperable lung cancer: patients' perspectives of how it affects their life situation and quality of life. Acta Oncol 47:862-869

32. Schou KC, Hewison J (1998) Health psychology and discourse: personal accounts as social texts in grounded theory. $\mathrm{J}$ Health Psychol 3:297-311

33. Schou KC, Hewison J (1999) Experiencing cancer: quality of life in treatment. Open University Press, Buckingham

34. Bailey DE, Mishel MH, Belyea M et al (2004) Uncertainty intervention for watchful waiting in prostate cancer. Cancer Nurs 27:339-346

35. Wallace M (2003) Uncertainty and quality of life of older men who undergo watchful waiting for prostate cancer. Oncol Nurs Forum 30:303-309

36. Lin CC, Tsay HF (2005) Relationships among perceived diagnostic disclosure, health locus of control, and levels of hope in Taiwanese cancer patients. Psychooncology 14:376-385

37. Swinney JE (2002) African Americans with cancer: the relationships among self-esteem, locus of control, and health perception. Res Nurs Health 25:371-382 
38. Gullatte MM, Phillips JM, Gibson LM (2006) Factors associated with delays in screening of self-detected breast changes in African-American women. J Natl Black Nurses Assoc 17:45-50

39. Gotay CC, Shimizu H, Muraoka M et al (2004) Health attitudes and behaviors: comparison of Japanese and Americans of Japanese and European ancestry. Health Place 10:153161

40. Bauvet F, Awada A, Gil T, Hendlisz A (2009) Therapeutic consequences of molecular biology advances in oncology. Bull Cancer 96:59-71
41. Pannala R, Basu A, Petersen GM, Chari ST (2009) New-onset diabetes: a potential clue to the early diagnosis of pancreatic cancer. Lancet Oncol 10:88-95

42. De Boer MF, Ryckman RM, Pruyn JF, Van den Borne HW (1999) Psychosocial correlates of cancer relapse and survival: a literature review. Patient Educ Couns 37:215-230

43. Masters KS, Wallston KA (2005) Canonical correlation reveals important relations between health locus of control, coping, affect and values. J Health Psychol 10:719-731

44. Houldin AD (2003) Pflegekonzepte in der onkologischen Pflege. Hans Huber, Bern 